\title{
A pesquisa-intervenção na formação continuada de professores e o dispositivo de análise das práticas profissionais, de orientação psicanalítica: revisitando algumas questões e considerações
}

\section{Research-intervention in continuing teacher education and the analysis device of professional practices of psychoanalytic orientation: revisiting some questions and considerations}

\author{
Sandra Francesca Conte de Almeida ${ }^{1}$ \\ Rosana Márcia Rolando Aguiar²
}

\begin{abstract}
RESUMO
O objetivo do artigo é o de revisitar algumas questões e considerações de ordem teórico-metodológicas sobre a pesquisa-intervenção na formação continuada de professores, que utiliza o dispositivo de escuta e análise das práticas profissionais, de orientação psicanalítica, configurando um método clínico-ético. Este visa a tratar dos problemas relativos à práxis dos professores por meio da articulação entre subjetividade e práticas educativas. Para tanto, o trabalho perfaz um breve percurso histórico da análise das práticas profissionais, aborda alguns elementos conceituais de inspiração freudo-lacaniana introduzidos no dispositivo, tece algumas considerações sobre o manejo dos grupos clínicos e a formação do mediador desses grupos, concluindo sobre a relevância e os efeitos do dispositivo no desenvolvimento
\end{abstract}

DOI: $10.1590 / 0104-4060.49817$

1 Universidade Católica de Brasília. Programa de Pós-Graduação em Educação e do Curso de Psicologia. Brasília, Distrito Federal, Brasil. Asa Norte, SGAN 916, Módulo B, Av. W 5. CEP: 70790-160.E-mail: sandrafcalmeida@gmail.com

2 Universidade Católica de Brasília. Faculdade de Educação. Brasília, Distrito Federal, Brasil. EPTC QS 07 Lote 01. Águas Claras. CEP: 71966-700.E-mail: zanaguiar@gmail.com 
pessoal e no aperfeiçoamento profissional de professores e na re(significação) de suas práticas docentes.

Palavras-chave: pesquisa-intervenção; formação; professores; escuta; práticas profissionais.

\begin{abstract}
The aim of this paper is to revisit some of the issues and theoretical and methodological considerations about the research-intervention in the continuous training of teachers, using the listening device and the analysis of professional practices, with a psychoanalytic orientation, configuring a clinical-ethical method. It aims at addressing the problems related to the praxis of teachers through the articulation between subjectivity and educational practices. Therefore, this paper brings a brief history of the analysis of professional practices, discussing some conceptual elements of Freudian-Lacanian inspiration introduced into the device. In addition, it makes some considerations about the management of clinical groups and the formation of the mediator of these groups, concluding on the relevance and effects of the device in the personal and professional development of teachers and in the re(meaning) of their teaching practices.
\end{abstract}

Keywords: research-intervention; training; teachers; listening; professional practices.

O método de pesquisa-intervenção aplicado à formação continuada de professores permite, além da construção de um saber sobre si mesmo e sua prática profissional, a oferta de um trabalho de cuidado psíquico aos sujeitos participantes. Nessa modalidade de pesquisa e de intervenção, a prática é afetada pela subjetividade, pois considera-se que não é possível dissociar razão, emoção, afetos e representações recalcadas, componentes estruturantes do psiquismo humano. Contudo, nem sempre os registros da ordem do recalcado são considerados na pesquisa e na formação de professores, já que há uma verdadeira negação da existência dos conteúdos inconscientes que mobilizam o sujeito e que ultrapassam e afetam o seu querer consciente. Na nossa concepção, a subjetividade dos participantes e a do pesquisador/mediador é uma dimensão fundamental da pesquisa-intervenção.

Para o conceito de "intervenção" podem ser encontrados vários sentidos, mas Szymanski e Cury (2004) indicam que o conceito vem do latim interventio, que significa abono, fiança, garantia, tendo também os significados de estar entre, sobrevir e assistir. O dicionário Aurélio (FERREIRA, 1999) apresenta 
uma definição que se aproxima mais da ação do pesquisador na modalidade de pesquisa-intervenção participante: "interpor os bons ofícios". (FERREIRA, 1999, p. 359). Todavia, o pesquisador só terá a possibilidade de "interpor os bons ofícios" se estabelecer laços de confiança com as pessoas com as quais, durante algum tempo, trabalhará, já que o material de trabalho a ser produzido por ambas as partes é fruto de conteúdos subjetivos e de experiências pessoais e profissionais, advindos de configurações psíquicas pessoais, de características do próprio grupo e de condições institucionais.

Rocha e Uziel (2008) apresentam o objetivo da pesquisa-intervenção como sendo o de desnaturalizar o cotidiano e os modelos, crenças e valores estabelecidos na sociedade conseguindo-se, com isso, sair da normatização, do universal, em direção ao singular, alterando não somente o campo de pesquisa como também o pesquisador. Na perspectiva da psicanálise, para que a mudança ocorra é preciso confrontar-se com o inesperado, abrindo mão de uma segurança pré-estabelecida. Afinal, é com o imprevisto, com o inesperado, que a psicanálise intervém, já que são nessas circunstâncias que se aproxima do sujeito do inconsciente.

Pereira (2016) enfatiza que a pesquisa-intervenção está necessariamente atrelada "a processos de subjetivação e de desterritorialização, bem como de desnaturalização de si e do objeto investigado, de modo a poder levar o sujeito a produzir o que não se espera: uma novidade, um novo significante, uma fala plena. Algo que o surpreenda e o subjetive". (PEREIRA, 2016, p. 74).

Nas pesquisas-intervenção que conduzimos, na formação continuada de professores, o dispositivo utilizado é o da escuta clínica e análise das práticas profissionais, de orientação psicanalítica, isto é, um dispositivo clínico-ético.

Almeida (2003), ao discutir a ética do sujeito no campo educativo, define, citando dois fundadores da abordagem da formação clínica em ciências humanas, Cifali (1998; 2001, apud ALMEIDA, 2003) e Ardoino (1989, apud ALMEIDA, 2003), o que nomeia como procedimento ou dispositivo clínico-ético na formação de professores, que compreende a atitude clínica, que inclui o fazer-falar o outro e a escuta clínica dessa fala, na direção "que consiste em desenvolver a sensibilidade capaz de integrar saberes constituídos (mantidos em "suspensão") e saberes experienciais, vivenciais na relação com o outro". (ALMEIDA, 2003, p. 189). Para Cifali (2001), aponta Almeida, o dispositivo clínico-ético (de fala e de escuta) "é uma abordagem que visa a uma mudança, atém-se à singularidade, não tem medo do risco e da complexidade e coproduz um sentido do que se passa". (ALMEIDA, 2003, p. 188).

Martins (2003), também referenciado em Ardoino (1990), enfatiza que o lugar da escuta permite 
criar situações coletivas, espaços de construção de conhecimentos sobre si mesmo - sobre a escola, sobre as experiências dos envolvidos no processo educacional, etc. - de tal forma que os problemas vividos sejam amplamente discutidos e a busca de soluções para os mesmos, compartilhada. (MARTINS, 2003, p. 44-45).

Ainda, para o autor, o exercício da escuta clínica "tem como perspectiva desvelar dimensões do cotidiano escolar e das relações que o estruturam, até então impensadas, desconhecidas, mas que tangenciam as práticas que aí se estabelecem”. (MARTINS, 2003, apud ARDOINO, 1990, p. 44-45).

À atitude clínica, Almeida (2003) acrescenta o uso de relatos escritos (memórias educativas, registros escritos da prática, estudos de caso, micromonografias, registro de observações de campo, histórias de vida, dentre outros), que permitem a análise reflexiva e a criação de um espaço de sistematização e de teorização das práticas, colocando em movimento as identidades pessoal e profissional do professor, que poderão se (re)significar por meio da escrita dos fragmentos de sua memória cognitiva e afetiva.

No que diz respeito à análise das práticas, Beillerot (2000), ao refletir sobre essa expressão, aponta a importância desse dispositivo, dada à implicação subjetiva que o trabalho do professor impõe. Aborda o termo "prática" a partir da Filosofia, que o utilizou para diferenciar a vida ativa da contemplativa. A prática implica na aplicação de regras e de princípios que permitem efetuar concretamente uma atividade, possibilitando sua execução. Nessa perspectiva, a prática remete à ideia de ação e aponta para duas importantes dimensões que invocam a relação com o outro. De um lado, os gestos, as condutas e as linguagens e, do outro, as regras, objetivos, estratégias e ideologias.

Imbert (2000) propõe a reflexão sobre a prática, notadamente a pedagógica, centrada no termo práxis. O conceito, no sentido aristotélico, é uma atividade que não se esgota e nem se exaure na produção. A práxis, assim entendida, é uma atividade que questiona o modelo de uma relação instrumental, sujeito e objeto, com o fim de transformar a relação entre esses dois polos em uma interação entre sujeito e sujeito mediante um processo de subjetivação mútuo. O sujeito é compreendido como sujeito de si mesmo e da práxis, sendo constantemente transformado a partir da experiência e do engajamento no que ele faz e no que o faz, ao mesmo tempo.

Nessa perspectiva, a prática profissional não pode ser pensada a não ser em sua dimensão dialógica, social e psicológica, uma vez que transforma o ser humano. Há, em todo trabalho, uma determinada mobilização psíquica, que aponta para a importância de se pensar os efeitos da implicação dos registros 
consciente e inconsciente na prática profissional, já que esta é afetada pela realidade psíquica singular do sujeito.

Há que se considerar o contexto histórico fundante da modalidade de análise clínica das práticas profissionais, o Grupo Balint, que serviu de inspiração para desdobrar a experiência com educadores. O dispositivo de Grupo Balint tem seu início na formação de trabalhadores da saúde, como os médicos e os trabalhadores sociais, e influenciou o trabalho de formação com os pedagogos, conforme apontam Almeida (2011) e Imbert (2000).

Balint, psicanalista húngaro exilado em Londres, nos anos 50, iniciou seu primeiro projeto naquela cidade com a discussão sobre o trabalho de supervisão na formação de médicos, quando se confrontou com as dificuldades desses profissionais de se ocuparem com os problemas dos pacientes. (BALINT, 1957; BALINT; BALINT, 1961). Buscou então entender como poderia propor aos médicos em formação a tomada de consciência, intelectualmente e afetivamente, dos processos psíquicos inconscientes, sem a oferta de uma análise pessoal. A resposta à sua questão foi a de elaborar uma formação baseada essencialmente no estudo da contratransferência e de empregar no trabalho de grupo, inspirado no modelo da análise, a regra de que os participantes deveriam falar livremente a respeito de suas experiências, no trabalho, evocando a associação livre e, dessa forma, permitir a reflexão sobre a prática. (IMBERT, 2000).

Ainda na perspectiva histórica, a respeito do Grupo Balint, Blanchard-Laville (2012) aponta que, na visão de Michael Balint, os médicos poderiam explorar um pouco mais as implicações psicológicas envolvidas na relação médico-paciente, no âmbito de sua formação, sem, com isso, abandonar seu ofício, mas desenvolvendo uma sensibilidade maior na escuta de seus pacientes. A hipótese de Balint era a de que, na relação com o paciente, o médico teria a necessidade de desenvolver uma "atitude psicoterapêutica" para compreender melhor as questões demandadas pelos doentes e ajudá-los a encontrar, por eles mesmos, uma atitude propícia à própria demanda, atitude que permitiria ao paciente não se enredar na repetição de uma demanda insatisfeita. A autora relata que, a partir desse pensamento, Balint começou um estilo de trabalho de pesquisa e de formação de profissionais de saúde e de cuidado social, utilizando uma estrutura de grupo, composta por 8 ou, no máximo, 10 participantes.

Os grupos se reuniam em intervalos regulares, por um determinado tempo, na presença de um analista, que ocupava uma posição de líder, cuja denominação Balint julgava importante, pois designava uma responsabilidade ao animador do grupo. Assim, eram nessas reuniões que os médicos expunham seus casos e suas questões a respeito da prática profissional e do cotidiano no trabalho, que eram alvo de preocupação ou de conflitos pessoais. Por meio das falas e da escuta das histórias de vida dos profissionais participantes dos grupos, os próprios médicos 
se reportavam aos casos trazidos por uns e outros, apresentando possibilidades de encaminhamentos e de soluções, que eram discutidos no próprio grupo. Naquele contexto, cada participante estava presente com sua personalidade, seu modo particular de ser, sua subjetividade e, inclusive, suas convicções científicas, o que Balint denominava de contratransferência profissional.

Em Blanchard-Laville (2012) fica claro que o objetivo do dispositivo de trabalho não era o de modificar a maneira de pensar dos profissionais, nem suas atitudes a qualquer preço, mas de levá-los a uma consciência progressiva dos determinantes de sua prática, com vistas a trabalharem mais relaxados, menos preocupados, com menor rigidez, a ponto de se liberarem das restrições imaginárias e poderem, assim, exercer a profissão de médico de modo mais leve e tranquilo.

Balint se preocupava muito com a posição do psicanalista no grupo. Para ele, o mediador ocupa uma posição de pesquisador e não de educador. Seu papel é extremamente importante para desenvolver um ambiente acolhedor entre os participantes e de assegurar que a palavra circule livremente, à maneira da associação livre, com ausência de julgamento de valor e de críticas, de modo a fazer o grupo avançar em seu propósito.

A prática da formação profissional pela via desse dispositivo continuou com a mesma intenção, após a morte de Michael Balint. Particularmente, como aponta Blanchard-Laville (2012), as pesquisas em relação às situações fantasmáticas, que se desenvolvem e ocorrem nos grupos de análise clínica das práticas profissionais, avançaram muito, desde então, com os trabalhos de Wilfred R. Bion e no que concerne ao trabalho de equipe, com Didier Anzieu e René Kaës, na França. O dispositivo de Michael Balint se expandiu e é utilizado em diversos países na formação de profissionais como os médicos, dentistas, enfermeiros, psicólogos, pedagogos dentre outros.

Embora não se tratasse de um trabalho de análise, Balint reconheceu no dispositivo de formação profissional a eficácia do exercício da palavra. À evocação da regra primordial da Psicanálise, a associação livre, surgiriam as questões relativas ao trabalho. Assim, o trabalhador se autorizaria a falar no grupo clínico sobre a própria experiência no trabalho, que, com frequência, não se enquadra nas definições habituais que caracterizam um "bom profissional": competência, racionalidade e eficiência.

A principal característica do dispositivo Balint, portanto, é a articulação entre as dimensões profissionais e pessoais, aí compreendidas a realidade do mundo do trabalho e a subjetividade do trabalhador.

Contudo, em virtude da filiação freudiana-lacaniana, na sua formação em psicanálise, a primeira autora deste artigo introduziu nas pesquisas sob sua orientação, no campo da análise das práticas profissionais, dois recursos oriundos 
da teoria lacaniana, a saber, o conceito de confrontação e o método da conversação. Tais recursos não invalidam e muito menos negam a origem histórica e o valor do dispositivo concebido e posto em prática por Balint e seus seguidores, mas, antes, ampliam e incorporam à análise das práxis as contribuições teórico-clínicas advindas das formulações do campo da psicanálise lacaniana.

Lacan (1958/1998), no texto A direção do tratamento e os princípios de seu poder, estabelece uma diferença entre a interpretação e a confrontação. A interpretação incide sobre a divisão subjetiva do sujeito e seu assujeitamento ao Outro, pois "obra de um animal presa da linguagem, o desejo do homem é o desejo do Outro". (LACAN, 1958/1998, p. 634). Criticando "o lugar ínfimo que a interpretação ocupa na atualidade psicanalítica" (LACAN, 1958/1998, p. 598), Lacan a opõe à confrontação. Essa é definida como

[...] toda sorte de intervenções verbais que não são a interpretação: explicações, gratificações, respostas à demanda... etc., ou como um procedimento que impõe que até uma formulação articulada para levar o sujeito a ter uma visão (insight) de uma de suas condutas, sobretudo em sua significação de resistência, possa receber um nome totalmente diferente, como confrontação, por exemplo, nem que seja a do sujeito com seu próprio dizer, sem merecer o de interpretação, simplesmente por ser um dizer esclarecedor. (LACAN, 1958, p. 598).

Do ponto de vista da escuta clínica de docentes, em grupos de análise das práticas profissionais, no contexto de formação continuada, a confrontação do professor-sujeito com o seu dizer permite que ele tenha uma visão (insight) de sua conduta, como diz Lacan, que ele se implique subjetivamente, por meio da fala, naquilo que fez e faz, ao mesmo tempo em que mantém um questionamento e um distanciamento necessários em relação ao seu dizer e às suas escolhas e decisões, de modo a tornar possível a (re)construção de um saber-fazer na ação e uma articulação mais fecunda entre saberes teóricos e práticos. (ALMEIDA, 2012; AGUIAR; ALMEIDA, 2014; PAULO; ALMEIDA, 2015).

Com relação à conversação, Miller (2003) a define como um tipo de associação livre que obtém êxito, uma associação livre coletivizada:

Un significante llama a otro significante, no es tan importante quién lo produce y un momento dado. Si confiamos en la cadena significante, varios participan en lo mismo. Por lo menos es la ficción de la Conversación: 
producir - no una enunciación colectiva - sino una 'asociación libre' colectivizada, de la cual esperamos un cierto efecto de saber. Cuando las cosas pasan bien a mí los significantes de otros me dan ideas, me ayudan $\mathrm{y}$, finalmente, resulta - a veces - algo nuevo, un ángulo nuevo, perspectivas inéditas. (MILLER, 2003, p. 15-16).

Fagundes e Almeida (2016) esclarecem que Miller chama a atenção para o fato de que a conversação cria as condições para que não ocorra uma escuta passiva, convocando a todos para participar do dispositivo de associação livre coletivizada. Para que cada um dê a sua cota na produção da livre associação, no grupo, é preciso que o sujeito esteja tocado, afetado por algum insucesso que, de alguma forma, seja em comum com os demais. É fundamental, ainda, confiar no dispositivo da conversação, bem como existir um clima de confiança entre os participantes e entre esses e o mediador.

Na perspectiva dos dispositivos teórico-clínicos apontados, a análise das práticas profissionais, no campo educativo, tem como objetivo primeiro a implicação desejante do professor no seu ofício, atribuindo-lhe novos sentidos ao (re) significar sua prática, de modo a se reconhecer subjetivamente na sua profissão. O trabalho do mediador é o de propor que os professores falem a respeito das mais diversas situações ocorridas na sua prática docente, seja com os alunos, com os colegas, com a equipe pedagógica, seja com os gestores da instituição. Um convite a falar, sobretudo, de vivências, transformadas em experiências, que os tenham interrogado, que tenham representado algum enigma, que os tenham colocado em estado de angústia, de dúvida, de conflito, em termos de seus saberes, de seu desejo, de suas (in)decisões.

O desafio desse modo de intervenção consiste no manejo da mediação do grupo de professores. Almeida (2012) salienta que a análise clínica das práticas profissionais é baseada na ética do cuidado, e não na técnica, e que as dimensões pessoal e profissional não são vistas de forma separada, pois se imbricam mutuamente. Enfatizamos, com a autora, que o dispositivo é clínico, pois nele está presente o ethos do cuidado, do acolhimento, da escuta e o entendimento de que o professor é um sujeito (dividido pela linguagem, pelo inconsciente), que constitui sua subjetividade nas experiências vividas nas relações sociais e cuja história pessoal se enlaça com o percurso profissional.

Sobre a formação do mediador (ou animador) de grupos de escuta clínica e análise das práticas profissionais, de orientação psicanalítica, destacamos a importância desse profissional ter uma implicação desejante nos campos da formação de professores e da educação escolar, uma transferência com a psicanálise (em intensão e/ou em extensão), na condição de analista ou de analisante, e uma 
crença no seu objeto, o inconsciente, de modo a sustentar a oferta da palavra e a escuta do outro. Essas condições são fundamentais para o manejo do grupo e para assegurar uma posição ética discursiva, que faz semblante do discurso do analista, mas que envolve cuidado, ensino e transmissão daquele que anima o grupo, na condição de um Outro barrado.

Portanto, para escutar o professor e as formações do seu inconsciente, o mediador do grupo terá, ele mesmo, colocado seu próprio inconsciente à prova, para ser escutado. Port (2010) faz referência ao ato analítico formulado por Lacan, que não consiste em oferecer um rumo já determinado ou traçado pelo analista no trabalho de análise. Analogamente, na análise clínica das práticas profissionais, o mediador deixará em suspenso sua verdade. Nessa perspectiva, o lugar a ser ocupado, por meio da transferência, é o de Sujeito Suposto Saber. Certamente, esse ato implica certa transgressão ao a priori, ao já traçado, abrindo espaço para a criação de novos sentidos e lançando desafios a todo profissional que se proponha a ocupar a posição de mediador nos grupos de análise das práticas profissionais. Destarte, dá lugar ao próprio estilo de trabalho no manejo da transferência, à criação do novo no âmbito do percurso clínico empreendido e ao exercício da renúncia ao saber-todo, ao já estabelecido.

Destacamos, então, que um aspecto importante a ser considerado no trabalho com o grupo é o vínculo transferencial estabelecido entre o mediador e os professores, que emerge da confiança depositada na pessoa do animador. Assim como o analista reinventa a psicanálise a cada nova sessão com seu paciente, a cada sessão de grupo de análise das práticas o mediador deverá estar aberto ao novo e ao inesperado, pois novos conteúdos psíquicos inconscientes podem emergir e tensionar a relação transferencial estabelecida. Da mesma forma, é possível que se repitam "velhas" questões, oriundas de situações e de experiências diversas, no grupo de professores.

Baïetto e Gadeau (2002) apontam para o delicado manejo das questões que emergem no grupo, ligadas às situações que ocorrem no cotidiano da profissão docente e que afetam subjetivamente os professores. Em um primeiro momento, as questões podem ser colocadas no nível pessoal e virem a tornar-se, com o tempo, uma preocupação de todo o grupo. Os problemas levantados e escutados inicialmente como particular ao sujeito podem constituir-se como elementos de oferta de um espaço que permite o movimento de identificação com o problema focalizado, com vistas à busca compartilhada de solução. Contudo, o grupo pode validar ou não o que foi escutado pelo mediador. De todo modo, a escuta relança as questões emergidas dos professores. Assim, os movimentos defensivos que ocorrem no grupo podem ser minimizados, quando o mediador deixa deslizar as questões levantadas. 
Outra observação fundamental apontada pelas autoras, no manejo do grupo, é a atitude de evitar que o trabalho de reflexão sobre a prática se torne um espaço de produção de "receitas pedagógicas", o que pode mascarar a singularidade das falas dos professores e impedir o deslizamento das questões levantadas no grupo. É importante, ainda, enfatizam as autoras, estar atento às diferentes intervenções e evitar interpretações da fala dos professores. Acrescentamos que esse cuidado é essencial, pois o dispositivo em jogo é o da confrontação com o dizer e não o da interpretação, que ocorre no setting analítico clássico.

Notadamente, a ênfase no trabalho de formação continuada de docentes recai no fato de que as conversações incidem em processos vivenciados em situação profissional, portanto, essenciais na (re)construção da identidade profissional dos professores e nos encaminhamentos dos problemas, dificuldades e conflitos que dela se desdobram. O dispositivo, como apropriadamente lembra Blanchard-Laville (2007), é adequado ao trabalho com o sofrimento psíquico de docentes e, também, com a psicopatologia cotidiana profissional dos mesmos. A autora reafirma a relevância do dispositivo no percurso da formação docente, pois segundo ela a intervenção de orientação psicanalítica detém um grande potencial, que oportuniza possibilidades de reflexões, de encaminhamentos e de tomadas de decisões de natureza conceitual e prática, no que diz respeito à complexidade do processo educativo, à trajetória profissional e à vida pessoal do professor.

A respeito ainda das especificidades do dispositivo clínico utilizado no contexto da formação docente, Imbert (2000) refere que trabalhar com grupo de professores é particularmente desafiador, pois não são os saberes pedagógicos que estão em questão. $\mathrm{O}$ interesse não está nas teorias e o mediador deve se recusar a ocupar o lugar de Mestre no grupo. $\mathrm{O}$ autor salienta que o trabalho clínico com grupos de professores constitui um indispensável dispositivo de formação, pois o falar no grupo evoca componentes inconscientes, presentes no exercício da função docente, que os professores terão a oportunidade de verbalizar, de colocar em palavras, mas que são rotineiramente negados nos cursos tradicionais de formação docente, os quais, de um modo geral, excluem de seu programa as dimensões anímicas inconscientes do aparelho psíquico.

Nessa via, Almeida $(2012 ; 2011)$ esclarece que o dispositivo de análise clínica das práticas profissionais constitui uma modalidade de formação continuada que considera as peculiaridades do métier docente, por propiciar a (re) construção, em contexto, da identidade profissional do professor e a (re)significação de suas práticas, por meio de dispositivos que contemplam a colocação, em ato, de processos intra e intersubjetivos que atravessam o ofício docente. 
Finalizando, é importante lembrar que a prática da escuta, a ser exercida também pelo professor, é fundamental. A esse respeito, Imbert (2000), citando Balint, adverte que escutar é uma técnica muito difícil e sutil. Para o autor, o mediador deve incentivar o grupo para que a palavra circule livremente e, ao mesmo tempo, convidá-lo a exercitar a capacidade de escutar. Essa é uma nova atitude, que exige uma mudança considerável da posição do professor. No grupo, o desenvolvimento da capacidade de escutar cria uma atmosfera acolhedora, que facilita que cada um tome coragem para falar. O exercício da escuta, pelos professores, representa, contudo, um grande desafio, pois ele é um profissional da maestria, que cotidianamente faz muito mais uso da palavra do que da escuta do outro.

Resumidamente, o trabalho com grupos de escuta clínica de professores propõe que a palavra circule livremente, visando a sustentar e a ampliar o processo de simbolização, na medida em que as relações imaginárias/especulares e os ideais educativos são gradativamente desinflados. Isso implica em não obliterar a angústia com respostas ou decisões balizadas por regras exteriores ao grupo, por soluções mágicas, mas em canalizá-la para a expressão autêntica das diferentes formas de subjetivação presentes no grupo, por meio de novos significantes produzidos pelos sujeitos que falam, que tomam a palavra, na intenção de dar algum contorno à angústia que os mobiliza ou os paralisa no cotidiano da escola.

Nessa via, que aqui apresentamos brevemente, a pesquisa-intervenção, aplicada à formação continuada de professores, por meio da análise das práticas profissionais, tem se apresentado como um método clínico-ético capaz de mobilizar o professor a se confrontar com o seu dizer, pela expressão da palavra, que o interroga e faz enigma, e pela análise das mais diversas situações sobre as quais, todos os dias, é convocado a se posicionar nos ambientes da sala de aula e da escola. Ademais, permite que o professor se perceba implicado subjetivamente no seu ofício, reinterprete as representações de fracassos, conflitos e impasses e se reposicione face à impotência advinda do mal-estar na educação, que pode vir a ser (re)significado, então, como uma das condições inevitáveis do homem na civilização. Nesse registro, vislumbrado a partir de uma outra posição discursiva diante de seu próprio desejo e do desejo do Outro, opera-se uma abertura psíquica para invenções criativas e novos investimentos libidinais do desejo do professor, cuja ação passa a ser redimensionada e orientada para realizações possíveis mais gratificantes e prazerosas nos registros psíquicos do amor e do trabalho. 


\section{REFERÊNCIAS}

AGUIAR, R. M. R.; ALMEIDA, S. F. C. de. Violência na escola e sofrimento psíquico de professores: uma análise das práticas profissionais, de orientação psicanalítica. In: COLÓQUIO INTERNACIONAL DO LEPSI, 10. CONGRESSO DA RUEPSY, 5. CONGRESSO BRASILEIRO DA REDE INFEIES, 1. Crianças públicas, adultos privados. São Paulo: Universidade de São Paulo, FE/IP, 2014. Disponível em: <http://www3. fe.usp.br/secoes/inst/novo/eventos/detalhado.asp? num $=1875 \&$ cond $=11 \&$ some $=1>$. Acesso em: 20 de nov. 2016.

ALMEIDA, S. F. C. de. Formação continuada de professores: conhecimento e saber na análise clínica das práticas profissionais. Estilos da Clínica, v. 17, n. 1, p. 76-87, 2012.

ALMEIDA, S. F. C. de. Dispositivos clínicos de orientação psicanalítica na formação de professores: entre o cuidado, o ensino e a transmissão. In: ALMEIDA, S. F. C. de; KUPFER, M.C. M. (Orgs.). A Psicanálise e o trabalho com a criança-sujeito: no avesso do especialista. Rio de Janeiro: Wak, 2011. p. 27-44.

ALMEIDA, S. F. C. de. A ética do sujeito no campo educativo. In: ALMEIDA, S. F. C. de (Org.). Psicologia Escolar: ética e competências na formação e atuação profissional. Campinas: Editora Alínea, 2003. p. 179-184.

ARDOINO, J. L'analyse multiréférentielle des situations sociales. Psychologie Clinique, n. 3, p. 33-49, 1990.

BAÏETTO, M. C.; GADEAU, L. Questions relatives à l'élaboration d'une position clinique dans le cadre de l'analyse des pratiques éducatives. Recherche et Formation pour les professions de l'éducation. Analyses des pratiques: approches psychosociologique et clinique, Paris: INRP, n. 39, p. 9-26, 2002.

BALINT, M. The doctor, his patient and the illness. 2. ed. London: Pitman Medical, (1964, reprinted 1986), Edinburgh, Churchill Livingstone, 1957.

BALINT, M.; BALINT, E. Psychotherapeutic techniques in medicine. London: Tavistock publications, 1961.

BEILLEROT, J. L'analyse des pratiques professionelles: porquoi cette expression? In: BLANCHARD-LAVILLE, C. B; FLABET. D. (Eds.). Analyser les pratiques profissionnelles. Paris: L' Harmattan, 2000.

BLANCHARD-LAVILLE, C. B. Em defesa de uma clínica de orientação psicanalítica em Ciências da Educação. Estilos da Clínica, v. 12, n. 22, p. 208-223, 2007.

BLANCHARD-LAVILLE, C. B. Pour une clinique groupale du travail enseignant. Revue Cliopsy, n. 8, p. 47-71, 2012.

FAGUNDES, C.; ALMEIDA, S. F. C. de. A nova ordem simbólica e suas repercussões na função docente, no Ensino Superior. In: MEDEIROS, C. P.; ALMEIDA, S. F. C. de. 
(Orgs.). Psicanálise implicada: educar e tratar o sujeito. Curitiba: Juruá, 2016. v. 1. p. 65-89.

FERREIRA, A. B. H. Aurélio século XXI: o dicionário da língua portuguesa. 3. ed. Rio de Janeiro: Nova fronteira, 1999.

IMBERT, F. L'impossible métier de pedagogue. Issy-Les-Moulineaux: ESF Éditeur, 2000.

LACAN, J. A direção do tratamento e os princípios do seu poder. In: LACAN, J. Escritos. Rio de Janeiro: Jorge Zahar Editora, [1958] 1998. p. 591-652.

MARTINS, J. B. A atuação do psicólogo escolar: multirreferencialidade, implicação e escuta clínica. Psicologia em Estudo, v. 8, n. 2, p. 39-45, 2003.

MILLER, J.-A. Problemas de pareja, cinco modelos. In: MILLER, J.-A. La pareja y el amor: conversaciones clinicas com Jacques Alain-Miller em Barcelona. Barcelona: Eólia, 2003.

PAULO, T. S.; ALMEIDA, S. F. C. de. Violência e Escola: escuta de professores e análise das práticas profissionais, de orientação psicanalítica. Brasília: Liber Livro/Unesco, 2015.

PEREIRA, M. R. O nome atual do mal-estar docente. Belo Horizonte: Fino Traço, 2016.

PORT, I. F. Educar não é "preciso": ato educativo e eficácia simbólica no contexto da educação escolar. Tese (Doutorado em Educação). Universidade Federal do Rio Grande do Sul, Faculdade de Educação, Porto Alegre, 2010. Disponível em: <http://www.lume. ufrgs.br/bitstream/handle/10183/25840/000754856.pdf?sequence=1>. Acesso em: 20 nov. 2016.

ROCHA, M. L.; UZIEL, A. P. Pesquisa-intervenção e novas análises no encontro da Psicologia com as instituições de formação. In: CASTRO, L. R. de; BESSET, V. L. (Orgs.). Pesquisa-intervenção na infância e juventude. Rio de Janeiro: Nau/FAPERJ, 2008. p. 532-556.

SZYMANSKI. H; CURY, V. E. A pesquisa-intervenção em psicologia da educação e clínica: pesquisa e prática psicológica. Estudos de Psicologia, v. 9, n. 2, p. 355-36, 2004.

Texto recebido em 17 de dezembro de 2016. Texto aprovado em 03 de janeiro de 2017. 
